\title{
DE UN GRABADO DE RUBENS
}

\section{Eduardo Báez Macias}

En la revista Goya del año de 1977, en un número dedicado a Rubens, ${ }^{1}$ el historiador Alfonso E. Pérez Sánchez entra al estudio de la gran influencia que tuvieron los grabados de composiciones rubenianas en la producción de pinturas barrocas españolas, incluidas, claro está, las que se hicieron en América. Algo ya sabido, pero que no habíamos visto demostrado con el despliegue de ejemplos y conocimientos como los que aquí expone el profesor Pérez Sánchez.

Mucho se debe a que dichos grabados, que buen recurso constituyeron para salir al paso de los encargos, fueran copiados en toda su composición o sólo en alguno o varios motivos cuando el artista, con más circunspección, manejaba las estructuras con propia inventiva.

De las composiciones aludidas en el artículo, una que me ha interesado para escribir esta nota es La conversión de San Pablo, salida del buril de Schelte A. Bolswert, uno de los varios y excelentes grabadores de las obras de Rubens. Es la historia de Saulo que a la vista de Damasco cae anonadado por el resplandor del cielo, entre sus compañeros que oían la voz de Dios, pero sin verlo, que éste era un privilegio sólo a Saulo concedido (lámina 1 ).

Un apretado grupo de hombres y caballos llena el lado izquierdo del grabado, dividiéndolo casi en diagonal para dar la impresión de que el grupo es empujado, casi aplastado, por la irresistible fuerza sobrenatural que proviene de Dios. La erguida cabeza de un caballo encabritado, con su jinete y la bandera que otro sostiene al final, parecen formar una valla de resistencia, ya vencida, arrojada sobre el ángulo inferior izquierdo. El caballo de Saulo intenta ponerse de pie, mientras el jinete yace con la espalda en tierra, una pierna atrapada bajo el cuerpo del animal y la otra, casi dislocada, todavía sobre el lomo. El vigor y la fuerza expresiva del grupo bastarían para decir que es el momento culminante en que Saulo habla a Dios (¿quién eres tu, Señor?) al tiempo que el remolino de hombres y caballos se abate con violencia. El espacio a la derecha es

1 Pérez Sánchez, Alfonso E, "Rubens y la pintura barroca española", en Goya, Revista de Arte, núm. 140-141. Madrid, 1977, p 86-169. 
ocupado por un soldado que se esfuerza por dominar su cabalgadura y un perro que ladra participando en la confusión.

Pérez Sánchez ilustra y comenta la influencia del grabado en un lienzo de Murillo del Museo del Prado, en el que se aprovecharon, del grabado flamenco, la figura del apóstol, el soldado que lo levanta y el caballo, pero éste invertido, de manera que el esquema se hace más reposado, con esa propensión a representar los instantes anteriores o posteriores a la culminación de un acto. Aquí San Pablo, aunque todavía por el suelo, es ya un converso que tiende la mano implorando a Dios.

Otra pintura derivada del mismo grabado -aludida en el mismo artículo- es La conversión de San Pablo, en el Museo de Segovia, realizado por Francisco Camilo en 1667. Se varió la cabeza del caballo y la actitud de los soldados, dando a la composición una estructura piramidal. Ya Diego Angulo había advertido la influencia rubeniana, sobre dicha obra, de alguna estampa flamenca o italiana ${ }^{2}$

En México he encontrado dos copias del grabado de Bolswert, aunque supongo que por lo accesible del asunto se irán encontrando muchas más.

Una, bastante descuidada, expuesta al polvo y al exceso de luz, cuelga en la pared en el cubo de la escalera del edificio de la Mitra de Morelia. Es un lienzo grande, sin firma visible y copia fiel del grabado flamenco (lámina 2). El artista, que lo haría por encargo, no se atrevió ni a variar ni a inventar cosa alguna, excepto que lo pintó invertido por haberlo copiado de alguna segunda calcografía y no de un original. Bien mirado, es fácil percatarse de que tampoco puso mucho esmero en los gestos de los personajes, que resultan anodinos e inexpresivos.

La segunda pintura, anónima, pertenece a la parroquia de San Miguel del Milagro en Tlaxcala (lámina 3). Por el tema resulta ajeno al santuario cuya decoración original consistía en escenas alusivas al arcángel San Miguel y sus apariciones; pero debió llegar ahí en sustitución de alguno de los grandes lienzos de contexto sanmiguelesco que cubrían los muros del templo, y que por quién sabe qué malas artes desaparecieron.

Es una pintura descriptiva en la que fue aprovechado el grabado de Bolswert para el primer plano que describe la conversión de

2 Angulo finiguez, Diego, "Francisco Camilo", en Archivo Español de Arte, t 32. núm. 126 , p. 89 . 
Saulo. En el segundo plano, ocupando la mayor parte del área, se pintó la ciudad de Damasco, copiándola de algún dibujo de aquellos que ilustraban los libros de historia religiosa. Así se explica que la ciudad esté pintada detalladamente con su circuito de murallas, sus edificios, el rio con sus puentes que la cruza diametralmente y hasta un camello próximo a trasponer una de las puertas.

El grabado de Shelte A. Bolswert fue íntegramente aprovechado por el pintor, quien incluso completó las figuras de la izquierda que en el original están recortadas. Pablo, caído, pronuncia su segunda frase: Domine, quid me vis facere? (Señor, ¿qué quieres que yo haga?) en tanto que los soldados de su séquito intentan levantarlo.

El jinete, que se esfuerza por dominar el caballo que cocea, en el lienzo del santuario se ha desplazado al centro y el artista, para equilibrar la escena, ha llenado el espacio de la derecha con una escena consecuente en la que Pablo, cegado por el resplandor, camina sostenido por sus compañeros, después que Dios le ha mandado entrar a Damasco. Estas figuras, ya no copiadas del grabado, son de menor calidad. Es magnifico en cambio el soldado que al extremo derecho camina vigorosamente, apretando con la mano el puño de la espada. No hay duda que proviene de alguna otra estampa de la misma serie. Lo que resulta atroz es el perro; en el grabado se le ve asomando medio cuerpo, perfectamente integrado a la acción que se presenta, pues en la confusión que trae la caída de Saulo baja la cabeza, se agita y ladra. En el lienzo de Murillo del Museo del Prado reaparece dulcificado, como que las cosas ya estaban tranquilas y Pablo se había trocado de perseguidor en futuro propagador del cristianismo. Pero en San Miguel del Milagro se pintó totalmente desintegrado del grupo, como un pegoste y en actitud forzada. Hasta creo que el pintor se olvidó de él cuando hizo el cuadro y que fue posteriormente cuando se le agregó. No es ya el perro dócil, expresivo de la fidelidad, que suele verse en las estampas flamencas o en la pintura de Murillo, sino un perro de cierto aire canallesco y malévolo. 
DOI: http://dx.doi.org/10.22201/iie.18703062e.1979.49.1118 
DOI: http://dx.doi.org/10.22201/iie.18703062e.1979.49.1118

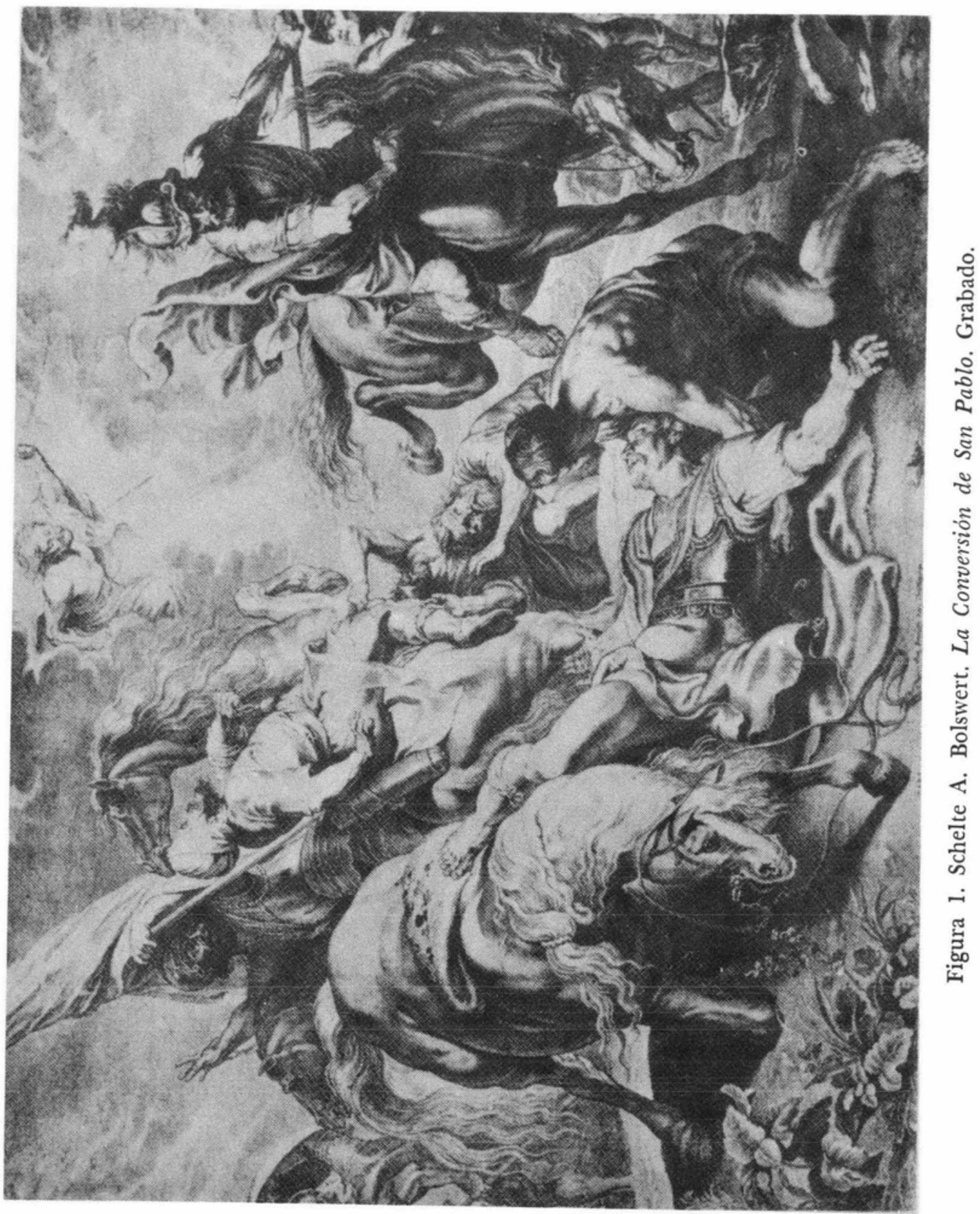


DOI: http://dx.doi.org/10.22201/iie.18703062e.1979.49.1118

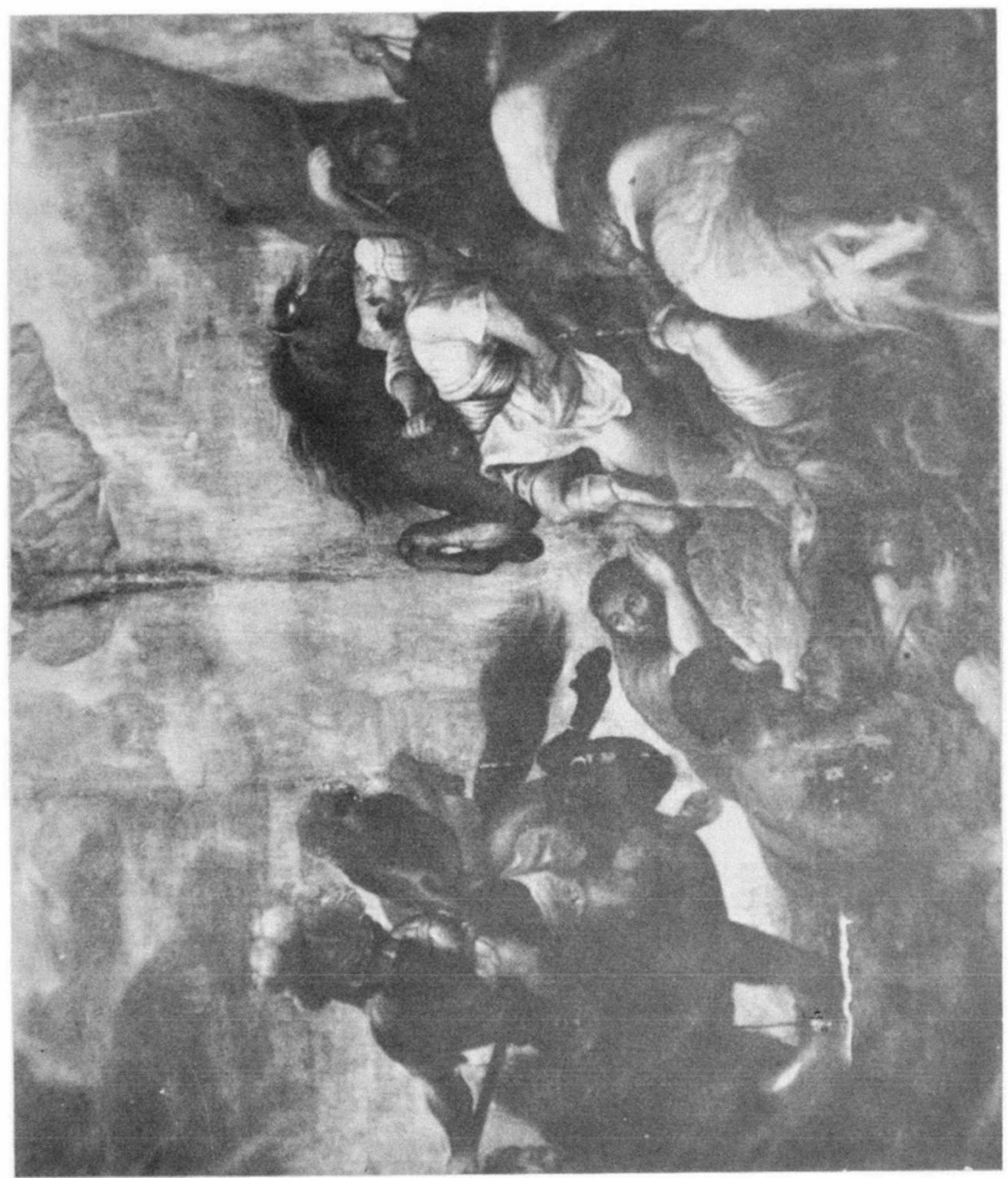

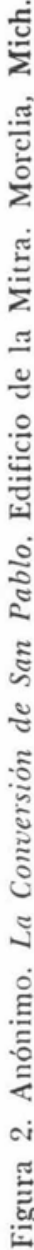


DOI: http://dx.doi.org/10.22201/iie.18703062e.1979.49.1118

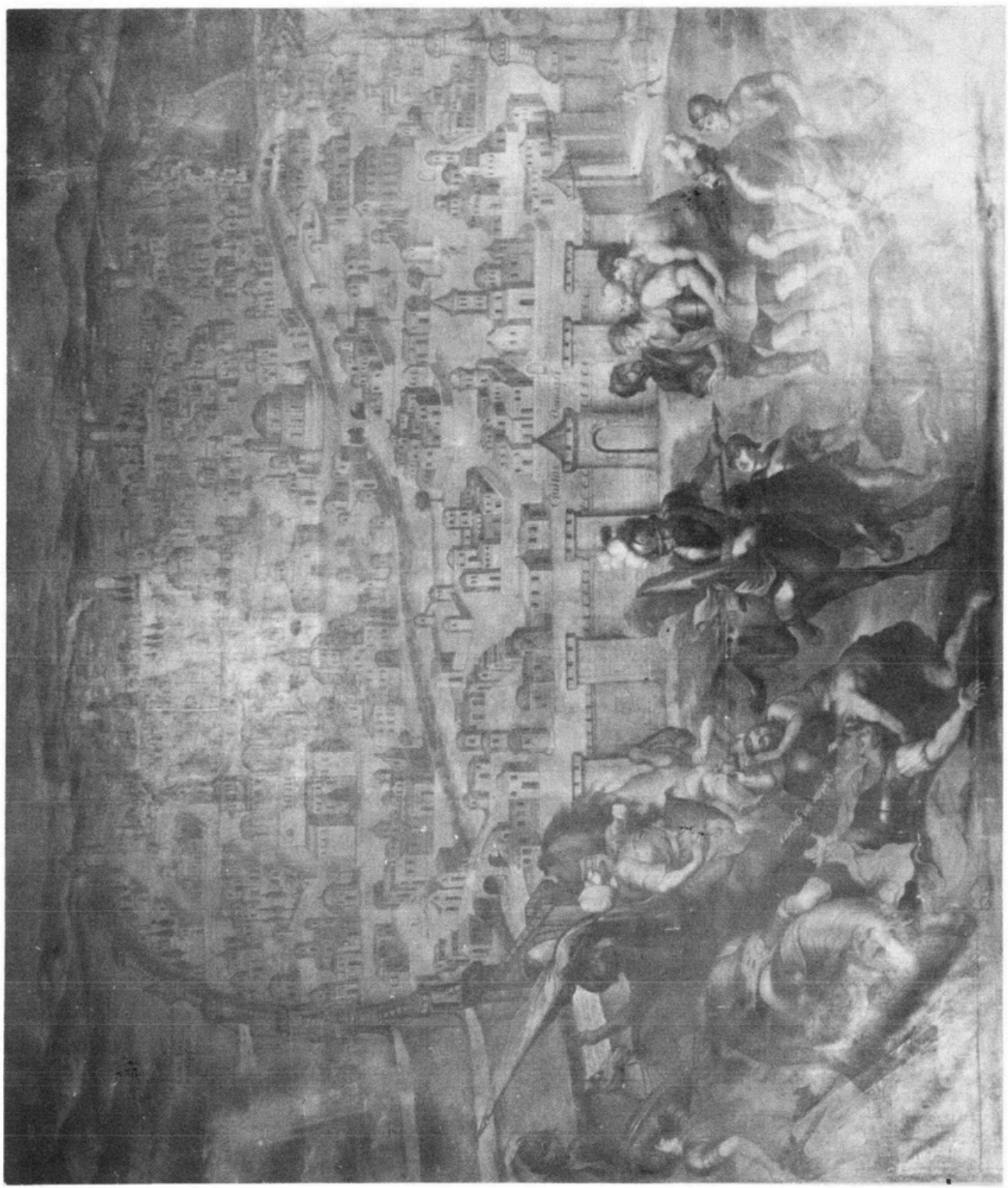

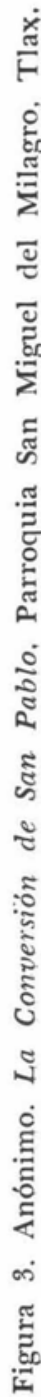


DOI: http://dx.doi.org/10.22201/iie.18703062e.1979.49.1118

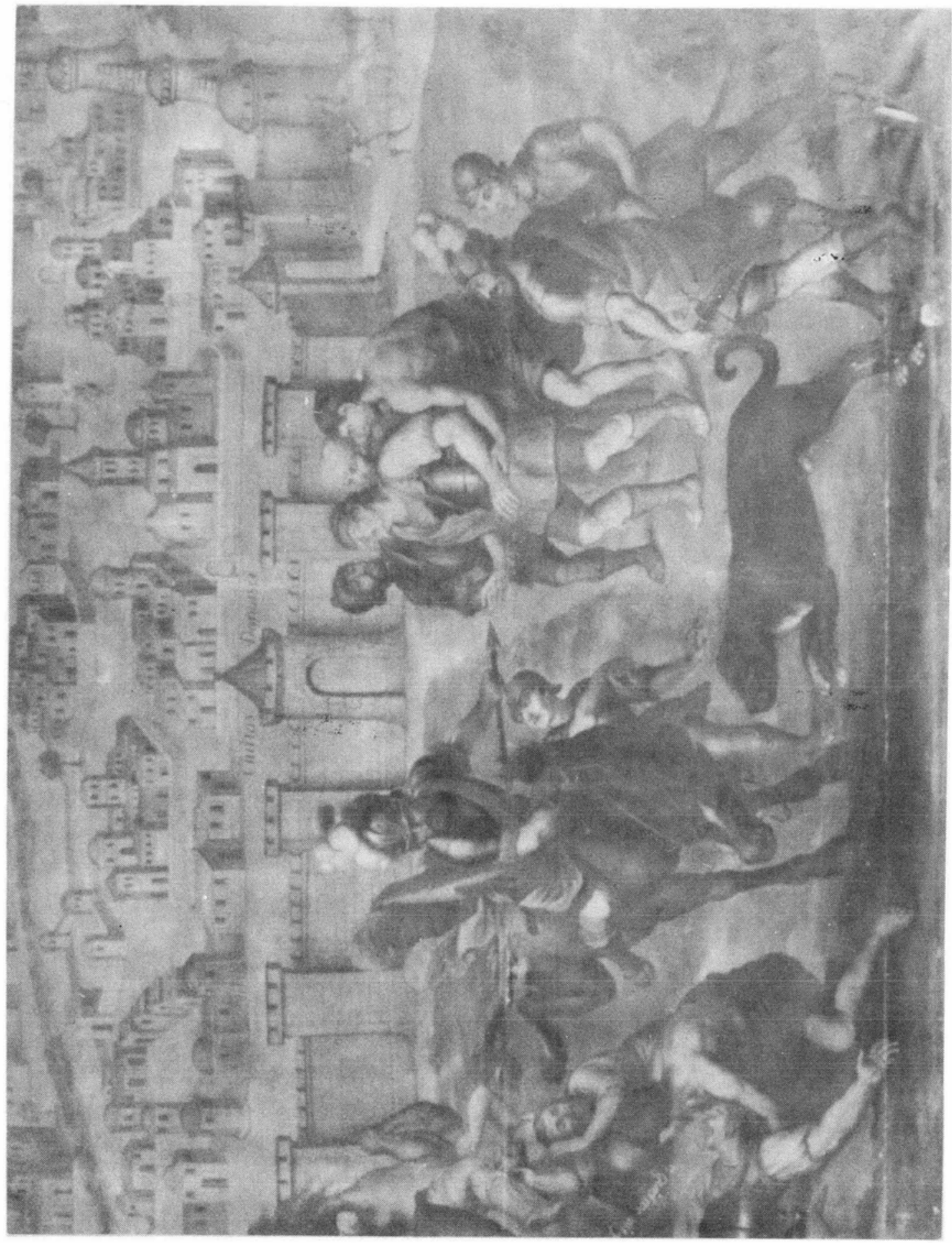

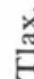

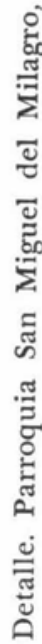

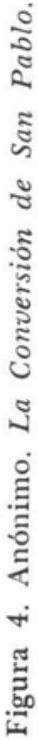

